EXPERIMENTAL STUDY

\title{
Expression of somatostatin receptor subtypes $1-5$ in pancreatic islets of normoglycaemic and diabetic NOD mice
}

\author{
E Ludvigsen ${ }^{1}$, M Stridsberg ${ }^{2}$, E T Janson ${ }^{2}$ and S Sandler ${ }^{1}$ \\ ${ }^{1}$ Departments of Medical Cell Biology and ${ }^{2}$ Medical Sciences, Uppsala University, Uppsala, Sweden \\ (Correspondence should be addressed to E Ludvigsen, Department of Medical Cell Biology Husargatan 3, Box 571 SE-75123 Uppsala, Sweden; \\ Email: Eva.Ludvigsen@medcellbiol.uu.se)
}

\begin{abstract}
Objective: Somatostatin acts on five specific receptors (sst1-5) to elicit different biological functions. The non-obese diabetic (NOD) mouse is an experimental model of type 1 diabetes. The aim of this study was to investigate whether the islet expression of sst1-5 is affected during the development of diabetes in NOD mice, with insulitis accompanied by spontaneous hyperglycaemia.

Methods: By immunostaining for sst1-5 the expression and co-expression together with the four major islet hormones in pancreatic islets were investigated in female and male NOD mice at different stages of disease. The NOD related non-diabetic ICR mouse was also examined.

Results: The islet cells of diabetic NOD mice showed an increased islet cell expression of sst $2-5$ compared with normoglycaemic female NOD mice. This correlated to increasing age and extent of insulitis. Major findings from the co-expression investigations were that sst 2 was expressed in a majority of $\beta$-cells in the normoglycaemic NOD mice, but absent in the $\beta$-cells in the diabetic NOD mice. A majority of the $\alpha$-cells expressed sst 2 and 5 in normoglycaemic and diabetic NOD mice. About $60 \%$ of $\delta$-cells showed co-expression of sst 4 and 5 in both normoglycaemic and diabetic NOD mice. $60 \%$ of pancreatic polypeptide (PP)-cells expressed sst 4 in both groups. Insulitis was found to be accompanied by a down-regulation of sst in normoglycaemic animals.

Conclusions: The difference in sst expression in the islets cells of diabetic mice may suggest either a contributing factor in the process leading to diabetes, or a defence response against ongoing $\beta$-cell destruction.
\end{abstract}

European Journal of Endocrinology $153445-454$

\section{Introduction}

Type 1 diabetes mellitus is caused by a destruction of the pancreatic $\beta$-cells, rendering the pancreas unable to synthesize and secrete sufficient amounts of insulin. The non-obese diabetic (NOD) mouse represents an experimental model of type 1 diabetes, which includes a gradual development of pancreatic insulitis accompanied with hyperglycaemia (1-4). The inflammatory process in the pancreatic islets of Langerhans of the NOD mouse starts around 3-4 weeks after birth. Antigen-presenting cells such as macrophages and dendritic cells appear early, followed by $\mathrm{CD} 4^{+}$ and $\mathrm{CD} 8^{+} \mathrm{T}$ - and B-cells (5). At an early stage the insulitis is usually located around the islets (peri-islet), and at about 10 weeks of age extensive infiltration of the pancreatic islets can be observed (intra-islet).

Somatostatin is a natural cyclic peptide inhibitor of pituitary, pancreatic, and gastrointestinal secretion, acting through five specific membrane receptors (sst1-5) (6-8). The ssts are widely distributed in many tissues and organs, such as the pituitary, thyroid, kidney, and lung (9-13). The different ssts are distinguished by their pharmacological properties, tissue distribution, and intracellular signalling pathways. Somatostatin is produced by the $\delta$-cells in the islets of Langerhans in the pancreas where it plays an important role in the control of both insulin and glucagon secretion (14). Immunohistochemical studies on rodent pancreas have demonstrated expression of sst2 on $\alpha$-cells and sst5 on $\beta$-cells, suggesting that sst 2 regulates glucagon secretion and sst5 insulin secretion $(15,16)$. This has also been confirmed by in vitro studies on isolated mouse and rat pancreatic islets $(17-20)$. Recently we have found that all five ssts are expressed in the pancreatic islets of $\mathrm{C} 57 \mathrm{BL} / 6$ mice and Sprague-Dawley rats (21). Furthermore, by using a double immunofluorescense method on pancreatic specimens from the rodents, we reported that the co-expression of sst with the four major islet hormones varied between species and sst subtypes (21).

In the present study we aimed to investigate whether the islet expression of different sst receptors may be affected during the development of type 1 diabetes. For 
this purpose we immunohistochemically investigated the distribution of sst receptors and the co-expression with the four major islet hormones in pancreatic islets in female and male NOD mice at different stages of disease. A related, but not insulitis- and diabetes-prone, mouse strain (ICR) was also examined.

\section{Materials and methods}

\section{Animals}

Inbred NOD mice (Biomedical Center, Uppsala, Sweden), originally obtained from the Clea Company, Aobadi, Japan, were used in this study. The cumulative incidence of diabetes of NOD mice in our colony is about $70 \%$ at 30 weeks of age in the females and less than $10 \%$ in the males. The animals had free access to tap water and pelleted food. All experiments were approved by the local animal ethics committee at Uppsala University. Altogether 142 pancreatic glands were collected from NOD mice (95 females and 47 males), ranging from 4 to 66 weeks of age (Table 1 ). The NOD mouse strain is derived from the ICR mouse, and therefore three groups of five female ICR mice, aged 6, 20 and 40 weeks, and two groups of five male ICR mice, aged 11 and 20 weeks, were studied as non-diabetic prone controls (Taconic Farm, Germantown, NY, USA). Before a mouse was killed by cervical neck distension a blood glucose determination (Medisense, Waltham, MA, USA) was performed on blood samples taken from the tail tip, and the weight of the mouse was measured. An NOD mouse was considered diabetic when the non-fasting blood glucose concentration exceeded $10 \mathrm{mM}$.

\section{Immunohistochemistry}

The production and specificity of subtype-specific somatostatin receptor antibodies has been described before $(11,21)$. The pancreatic specimens obtained were immediately fixed in $10 \%$ buffered formalin (Merck, Darmstadt, Germany) for $24 \mathrm{~h}$ at room temperature, and then changed to $70 \%$ ethanol and embedded in paraffin. Sections, $5 \mu \mathrm{m}$ thick, were cut and attached to POLYSINE ${ }^{\mathrm{TM}}$ glass slides (MenzelGläser, Braunschweig, Germany).

\section{Single-staining with sst 1 - 5 antibodies}

All pancreatic sections were single-stained for the five sst receptors (21). The immune reaction was amplified by an avidin-biotin complex coupled to alkaline phosphatase (Vectastain ABC-AP; Vector Laboratories, Burlingame, CA, USA) and visualized with Vector Red ${ }^{\circledR}$ (Vector Laboratories) as a substrate (21). It should be noted that when the sst-specific antibodies were preincubated with the peptides used for immunization the immunoreactivity for each receptor was blocked (data not shown (21)).

\section{Double immunofluorescence staining of sst 1-5 and islet cells}

To investigate the co-expression of sst1-5 on the islet cells we used the immunofluorescence method described previously (21). Five pancreatic specimens from normoglycaemic female NOD mice, five from diabetic female NOD mice in age group 4, and five from normoglycaemic female NOD mice in age group 1 were collected, embedded in paraffin, and stained for sst $1-5$ in a cocktail with chicken anti-insulin (1:750; Immunsystem, Uppsala, Sweden), chicken anti-glucagon (1:400; a kind gift from Associate Professor A Larsson; raised against human glucagon (Novo Nordisk, Bagsvaerd, Denmark)), sheep anti-somatostatin (1:25; Guildhay, Guildford, Surrey, UK), or sheep antipancreatic polypeptide (PP) (1:25; SeroTech, Oxford, UK) as described previously (21). The immune reaction was visualized by a cocktail consisting of secondary antibodies: Cy3-conjugated donkey anti-rabbit IgG (1:100) and Cy2-conjugated donkey anti-sheep IgG (1:100) or Cy2-conjugated donkey anti-chicken IgG (1:100; all from Jackson ImmunoResearch, West Grove, PA, USA). The specificity of the commercial anti-hormone antibodies were tested by using different dilutions of the antibodies as well as by omitting the primary antibodies.

\section{Morphological evaluation}

Light-microscopic evaluation Pancreatic islet mononuclear cell infiltration was ranked according to an

Table 1 Age, sex, and blood glucose concentrations of the NOD mice included in this study.

\begin{tabular}{|c|c|c|c|c|c|c|c|}
\hline \multirow[b]{2}{*}{ Group } & \multirow[b]{2}{*}{ Age (weeks) } & \multicolumn{2}{|r|}{ Females } & \multicolumn{2}{|r|}{ Males } & \multicolumn{2}{|c|}{ Diabetic females } \\
\hline & & $n$ & Blood glucose (mM) & $n$ & Blood glucose (mM) & $n$ & Blood glucose (mM) \\
\hline 1 & $4-7$ & 10 & $6.1 \pm 0.2$ & 11 & $7.0 \pm 0.2$ & - & - \\
\hline 2 & $8-12$ & 5 & $5.3 \pm 0.5$ & 10 & $6.2 \pm 0.2$ & - & - \\
\hline 3 & $13-16$ & 9 & $6.2 \pm 0.5$ & 1 & $5.5 \pm 0.0$ & 2 & $10.6,28.8$ \\
\hline 4 & $17-20$ & 6 & $5.7 \pm 0.2$ & 8 & $6.1 \pm 0.1$ & 12 & $26 \pm 0.2$ \\
\hline 5 & $21-25$ & 4 & $5.7 \pm 0.4$ & 2 & $5.2,6.1$ & 9 & $26 \pm 0.9$ \\
\hline 6 & $26-35$ & 14 & $6.2 \pm 0.3$ & 14 & $6.4 \pm 0.3$ & 5 & $18 \pm 2.9$ \\
\hline 7 & $36-66$ & 16 & $6.9 \pm 0.3$ & 1 & $6.3 \pm 0.0$ & 3 & $21 \pm 3.1$ \\
\hline
\end{tabular}


arbitrary scale $(\mathrm{A}-\mathrm{C})$. Rank A denotes no apparent lymphocytic infiltration within and surrounding the pancreatic islets; rank B denotes $10-50 \%$ of the islets infiltrated, mainly in the peri-islet area; rank $\mathrm{C}$ denotes $>50 \%$ of the islets affected including intra-islet infiltration. It should be noted that within the pancreas of an animal ranked $\mathrm{B}$ or $\mathrm{C}$ there could appear occasional islets free of cell infiltration. Intensities of the sst immunoreactivity were scored semiquantitatively: +++ , strong positive immunoreactivity; ++ , clear positive immunoreactivity; + , weak positive immunoreactivity; -, not detected. Also, the location of the positive immunoreactivities of sst were scored (centre/periphery), referring to whether the sst expression was distributed in the centre of the islet or only in the periphery.

Evaluation of immunofluorescence The pancreatic sections were examined in a Leica Leitz DMR fluorescence microscope (Leica Microsystems, Wetzlar, Germany) equipped with filters of 492-510 nm for Cy 2 (green) and 550-570 nm for Cy3 (red). Pictures from a Zeiss Axiocam camera (Carl Zeiss, Oberkochen, Germany) of each pancreatic islet, using both filters, were merged together with Adobe Photoshop 7.0 software (Adobe, San Jose, CA, USA); a yellow colour indicated co-expression of an sst subtype with any of the four islet hormones tested in this study. The results are expressed as a percentage of sst-positive cells in relation to the total number of the respective islet cell type in a specific pancreatic islet.

The pancreatic sections and the different rankings were evaluated with the examiner being unaware of the origin of the sections and the identity of the antibody used. Sections from each pancreas were stained with each antibody, and mostly about 8-10 islets were analysed per animal. However, the diabetic animals had a lower number of islets than the normoglycaemic animals and thus in some diabetic mice fewer than 10 islets were examined. Because the islets in a given section varied in size, they were selected to include both large and small islets.

\section{Statistical analysis}

Statistical analysis was performed by comparing groups of data in Student's unpaired t-test or the Fisher's exact test, where $P<0.05$ was regarded as significant. The computer program used was SigmaStat 2.0 (SPSS Science Chicago, IL, USA).

\section{Results}

\section{Animals}

The NOD mice were classified into three groups: females, males, and diabetic females. Moreover, the mice were subdivided according to age into seven groups. In Table 1 the number and ages of the female and male NOD mice in each group are seen, as well as the mean blood glucose concentration for each group. For the study animals were collected at various occasions and among the females 31 out of 95 (33\%) were diabetic on the particular days of organ collection. None of the males were diabetic. Diabetic females had an increased blood glucose concentration with a mean peak level of about $26 \mathrm{mM}$ in age groups 4 , and 5. The normal females and males remained normoglycemic with a mean blood glucose concentration of $6 \mathrm{mM}$. Since female NOD mice have a higher risk of developing diabetes than males, we wanted to compare normoglycaemic female and male NOD mice to investigate whether there were any differences in sst expression. No such alterations were found and therefore, for purpose of clarity, we only presented data comparing normoglycaemic NOD females with diabetic NOD female mice, with exception of Fig. 3 (see below).

\section{Evaluation of insulitis}

Figure 1 shows the evaluation of insulitis in relation to age and normoglycaemia or diabetes in the different groups. Among normoglycaemic females only young mice (age groups 1-3) comprised animals with a normal pancreas without any apparent infiltration of immune cells in the islets of Langerhans (rank A). None of the older females displayed a pancreas without
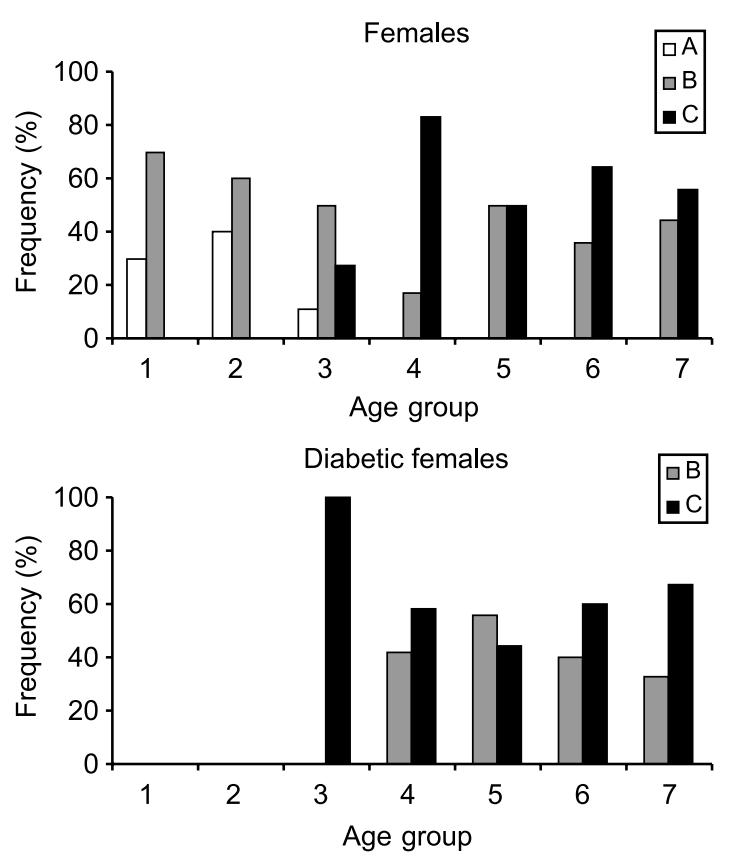

Figure 1 Frequency (percentage of animals) and rank of insulitis in different age groups of normal and diabetic female NOD mice. White bars denote essentially no cell infiltration, (rank A); grey bars denote $10-50 \%$ of islets infiltrated mainly in the peri-islet area (rank B); black bars denote $>50 \%$ of islets infiltrated, and to a large extent in an intra-islet location (rank C). 
any invading immune cells. Of normal females in age group $1,70 \%$ were scored $\mathrm{B}$, and this declined to $44 \%$ in the oldest age group. With more advanced age the predominating rank of insulitis became $\mathrm{C}$. The highest frequency of normoglycaemic female NOD mice scored $C$ was found in age group $4(83 \%)$. None of the diabetic female mice showed a normal pancreas without immune cells. In age group 3 all diabetic NOD mice were scored rank $\mathrm{C}$ and in age groups $4-6$ insulitis score B and $\mathrm{C}$ were almost equally distributed. For age groups 6 and 7 about two-thirds of the animals were scored $\mathrm{C}$.

\section{Expression of sst in pancreatic islets of NOD mice}

Figure 2 demonstrates the immunohistochemical staining for all five sst subtypes in a 22-week-old diabetic female NOD mouse with insulitis; that is, rank C. sst1 and 4 showed a weak positive immunoreactivity in the pancreatic islets, whereas sst 2,3 , and 5 revealed strong expression. The expression of sst $1-4$ seems to be present in the entire islet, whereas sst5 revealed a stronger central immunoreactivity in the islets. Note that one islet (sst2) did not appear to be inflamed; however, it was not a consistent finding that such islets were more intensely stained. Moreover, the acinar cells were frequently stained for sst 2 in the NOD mice.

The expression of sst subtypes, irrespective of age and rank of insulitis, in islets from normoglycaemic female and male and diabetic female NOD mice is shown in Fig. 3. The sst 1 receptor was equally abundant in the groups. However, there was a difference in sst2-5 expression between diabetic and normal females, and the same was found for sst $3-5$ when diabetic females were compared with males. There was no difference in this context when comparing normal female and male NOD mice. sst4 was the subtype that exhibited
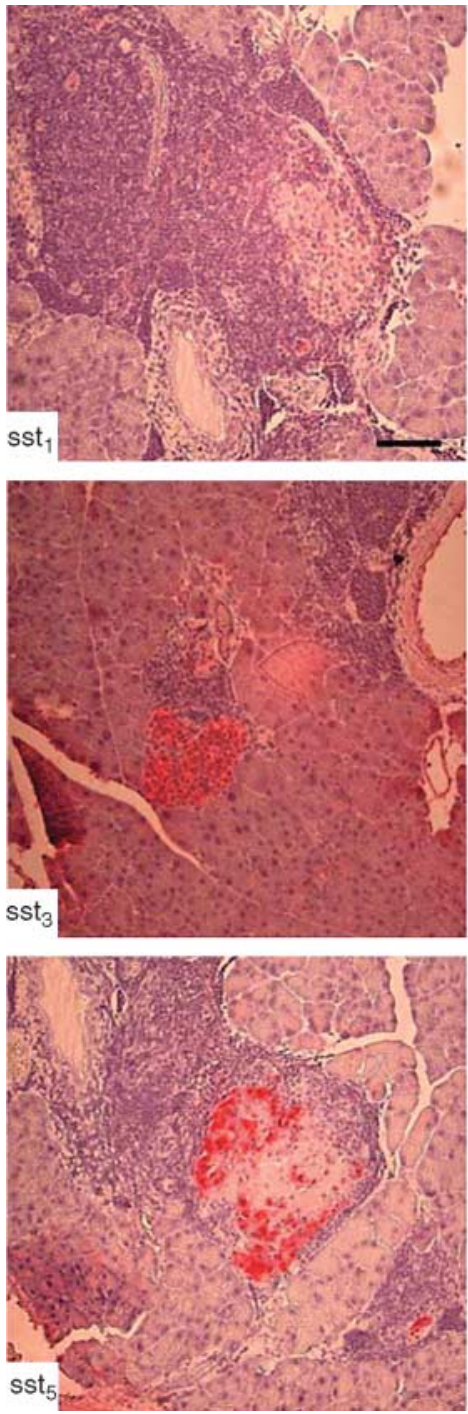
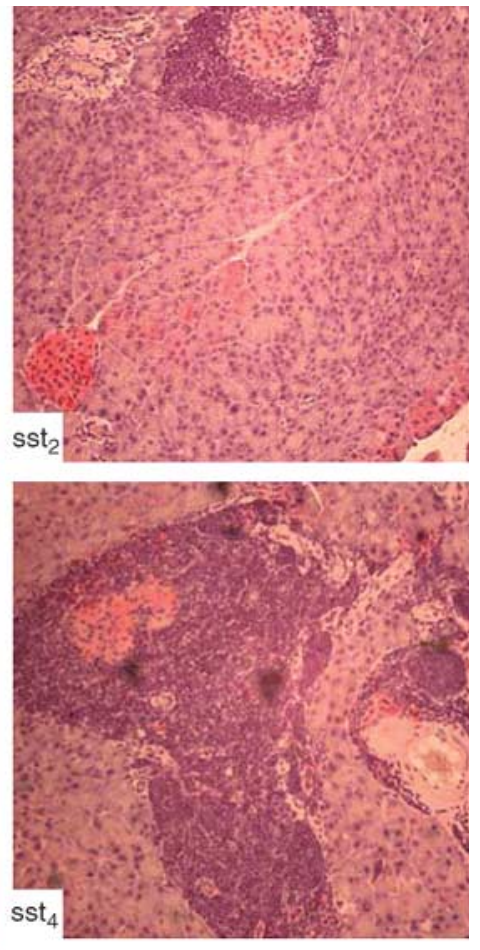

Figure 2 The immunohistochemical staining for all five sst subtypes in a 22-week-old diabetic female NOD mouse with insulitis rank $C$. sst 1 and 4 showed a weak positive staining in the pancreatic islets, whereas sst2, 3, and 5 revealed strong expression. The expression of sst1-4 seems to be in the entire islet, whereas sst5 revealed a stronger peripheral staining than in the centre of the islet. Scale bar, $50 \mu \mathrm{m}$. 


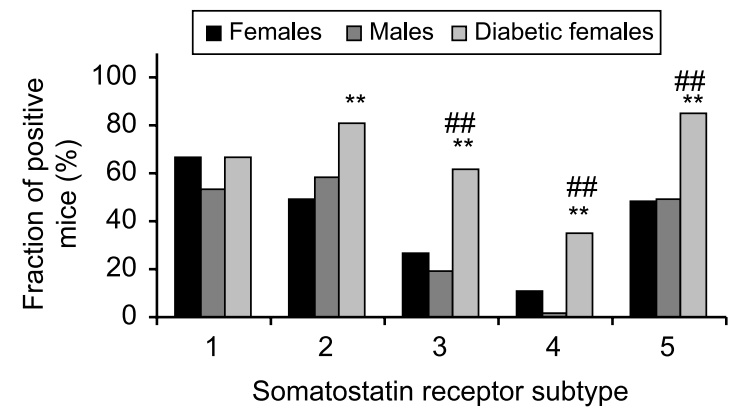

Figure 3 Fraction of mice showing positive islet staining for different sst receptor subtypes in normal female (black bars; $n=64$ ), normal male (dark-grey bars; $n=47$ ), and diabetic female (lightgrey bars; $n=31$ ) NOD mice. ${ }^{* \star} P<0.01$ versus normal females; $\# \# P<0.01$ versus normal males using Fisher's exact test.

the lowest frequency of expression, and in the normoglycaemic animals this receptor was found in only a minor fraction of the islets.

\section{Expression of sst in pancreatic islets in relation to rank of insulitis}

The pancreatic islets from each NOD mouse were ranked for insulitis according to an arbitrary scale $(\mathrm{A}-\mathrm{C})$, as detailed in the Materials and methods section. In the same pancreatic section an evaluation of sst expression was also performed. The expression of the five ssts in pancreatic islets of NOD mice scored with insulitis rank $\mathrm{B}$ and $\mathrm{C}$ is given in Fig. 4. This rank may correspond to an early phase in the progression of diabetes. Nevertheless it should be noted that some diabetic females received this score. There was no difference in sst1 and 2 expression in islets of diabetic females as compared with normoglycaemic mice with rank B. However, sst3, 4, and 5 expression was higher in islets of diabetic compared with normal females. In glands with more extensive insulitis, rank $\mathrm{C}$, the only sst receptor that became significantly increased in diabetic compared with normal females was the sst 2 receptor.

\section{Expression of sst in pancreatic islets in relation to age}

The expression of sst $1-5$ has been stratified according to age group of the NOD mice. A few sst receptors showed a significant change in the diabetic group in certain age groups (data not shown). An overall impression of the data may suggest that, with increasing age and the presence of diabetes, an increased fraction of mice showed positive sst3, 4, and 5 staining (data not shown). As a control, 15 female ICR mice were killed at 6,20 , and 40 weeks of age (all $n=5$ ). They had mean blood glucose concentrations of $9.9 \pm 0.4, \quad 7.2 \pm 0.1$ and $6.4 \pm 0.3 \mathrm{mM}$, respectively. Similarly we also studied sst receptor expression in 10
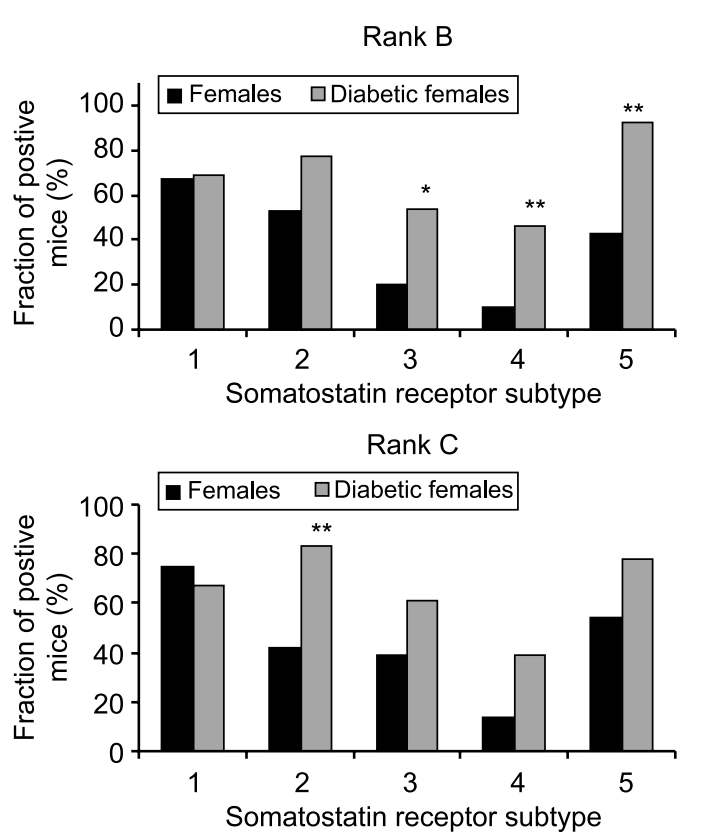

Figure 4 Top panel: fraction of all NOD mice included in the study showing positive islet staining for different sst receptor subtypes in normal females (black bars; $n=30$ ) and diabetic females (grey bars; $n=13$ ) with insulitis rank B. Bottom panel: similar evaluation for insulitis rank $\mathrm{C}$ was made for normal females (black bars; $n=28$ ) and diabetic females (grey bars; $n=18$ ). ${ }^{\star} P<0.05$,

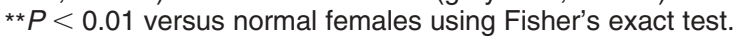

male ICR mice killed at 11 and 20 weeks of age (both $n=5$ ), with mean blood glucose concentrations of $9.1 \pm 0.6$ and $7.6 \pm 0.5 \mathrm{mM}$, respectively. None of the ICR mice had any infiltration of immune cells in the pancreatic islets, and were therefore all ranked A. Statistical analysis of data for female ICR mice, summarized in Fig. 5A, did not reveal any difference in sst expression, including sst3, when comparing the 6-week-old ICR mice with the older ICR mice aged 20 and 40 weeks. Moreover, Fig. 5B shows that there was no alteration of any of the five ssts expressed when comparing 11-week-old male ICR mice with 20-week-old male ICR mice. Thus, when we studied the influence of age in the ICR mice, which are genetically related but not diabetes- or insulitis-prone, we did not find that islet sst receptor expression varied with age.

\section{Double immunofluorescence staining}

To further investigate the influence of diabetes on the islet structure and sst expression pattern, normoglycaemic and diabetic NOD mice were stained using an immunofluorescence method. For this purpose mice in age group 4 were selected. Figure 6 shows the quantitative analysis of the pancreatic islet co-expression of sst receptor subtypes with insulin (Fig. 6A), glucagon (Fig. 6B), somatostatin (Fig. 6C), and PP (Fig. 6D). Fig. 6A shows that sst 2 is expressed in a majority of $\beta$-cells in the nor- 

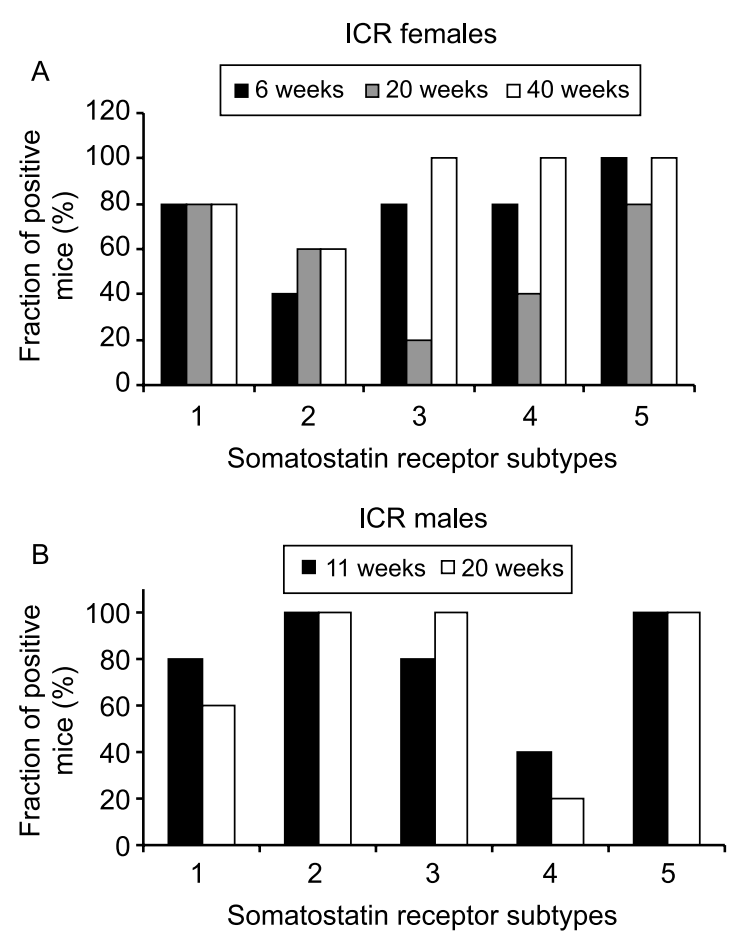

Figure 5 Fraction of ICR mice showing positive islet staining for different sst receptor subtypes in (A) 6- (black bars), 20- (grey bars), and 40-week-old females (white bars) and in (B) 11- (black bars) and 20-week-old males (white bars). All groups, $n=5$. moglycaemic NOD mice, whereas none of the few $\beta$-cells still existing in the diabetic NOD mice expressed this receptor subtype. The other receptors were expressed in about half of the $\beta$-cells in pancreatic islets of normoglycaemic females, whereas less than $20 \%$ of the $\beta$-cells in diabetic NOD mice co-expressed sst1, 3 and 5. The sst 4 receptor was not co-expressed at all in the $\beta$-cells of the diabetic mice. Fig. 6B shows the co-expression of sst1-5 together with glucagon-positive cells. All five ssts were expressed to a higher degree in the islets of diabetic NOD mice compared with normoglycaemic females. sst 2 and 5 were expressed in the majority of $\alpha$ cells in both study groups.

Figure 7 shows the merged picture of Cy3-conjugated immunofluorescence distribution of sst1-5 (red) together with Cy2-conjugated glucagon antibody (green) in a representative islet sample of a normoglycaemic NOD mouse (Fig. 7A-E) and a diabetic NOD mouse (Fig. 7F-J). Co-expression is demonstrated by a yellow colour. It should be noted that the islet structure is altered in diabetic NOD mice, where the $\alpha$-cell mass appears to be expanded and becomes more centrally located in the islets, replacing the vanished $\beta$-cells. The co-expression of sst $1-5$ on somatostatinsecreting cells (Fig. 6C) shows that sst4 and 5 were expressed in about $60 \%$ of the $\delta$-cells in both normoglycaemic and diabetic NOD mice. However, sst1 and 3 were expressed to a higher degree in normoglycaemic
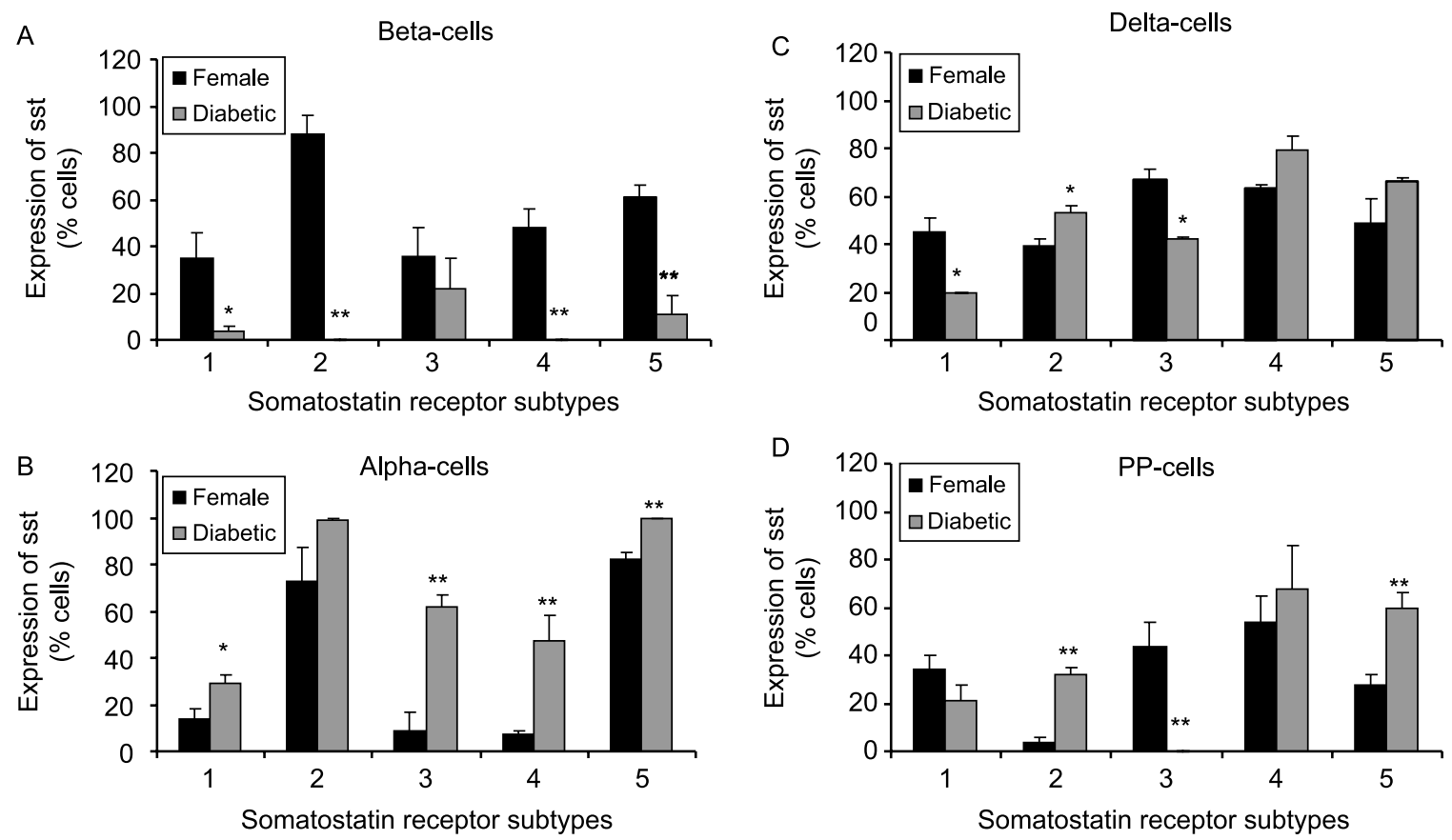

Figure 6 Quantitative analysis of the expression of sst1-5 in $\beta$-cells (A), $\alpha$-cells (B), $\delta$-cells (C), and PP cells (D) in pancreatic islets of normoglycaemic female NOD mice (black bars; $n=5$ ), and diabetic NOD mice (grey bars; $n=5$ ) from age group 4 . Bars represent the means \pm S.E.M. from the percentage of cells positive for a given sst subtype. ${ }^{\star} P<0.05,{ }^{\star \star} P<0.01$ versus normal females using Student's unpaired $t$-test. 
animals, whereas expression for sst 2 showed the opposite change. The PP cells were co-expressed with sst 4 to about $60 \%$ in both groups (Fig. 6D). sst2 and 5 had a higher fraction of co-expression in the PP cells in diabetic NOD mouse islets, whereas sst 3 was not expressed at all in the diabetic group. sst1 was expressed to about $20-30 \%$ in both study groups. The inflammatory cells may also influence the expression of sst. Therefore we immunofluorescence-stained five normoglycaemic female NOD mice without any insulitis (rank A) from age group 1 and compared the results with normoglycaemic females having immune-cell infiltration (rank $\mathrm{B} / \mathrm{C}$ ) in age group 4 . These results are summarized in Table 2. sst1 receptors were found to be less expressed on $\beta$-cells in animals with cellular infiltration compared with normal animals. Also in $\alpha$-cells the expression of sst1, as well as that of sst3, was decreased in the islets of inflamed mice. sst 2 and 5 were expressed in a majority of the glucagon-secreting cells in both the normal animals and animals with islet infiltration. The sst1 receptor was expressed in the $\delta$-cells to a lower degree in animals with immune cells. The same pattern was seen for sst2. The other receptors were expressed to almost the same extent. In the PP cells sst2 and 5 receptors were expressed less in the mice with (peri)insulitis.

\section{Discussion}

The NOD mouse model is a useful tool for the study of type 1 diabetes, since it shares many features of the human disease. In our study we have investigated the distribution and expression of sst $1-5$ in NOD mouse islets in relation to gender, age (data not shown), rank of insulitis (Fig. 4 and Table 2), and presence or absence of diabetes (Figs 3 and 6). Presently the NOD mice were collected on different occasions and among the females 31 out of 95 (33\%) were diabetic on the particular days of organ collection. None of the males were diabetic. Since female NOD mice have a higher risk of developing diabetes than males, we wanted to compare normoglycaemic female and male NOD mice to investigate whether there were any differences in sst expression. No such alterations were found, however, suggesting that the difference of sst subtypes expression in the diabetic animals is due to the pathogenesis and/or symptoms of type 1 diabetes and not due to a difference in gender. The expression of sst $1-5$ has been stratified according to age group of the NOD mice (data not shown). A few sst receptors showed a significant or near-significant change in the diabetic group in certain age groups. An overall impression of the data may suggest that with increasing age and the presence of diabetes an increased fraction of mice showed positive sst 3,4 , and 5 staining. The fact that some apparent differences between normoglycaemic and diabetic females are not statistically significant can be attributed to low numbers of mice in certain age groups. The NOD mouse is derived from the non-diabetic prone ICR mouse, and this strain could thereby be studied as a control. We thus examined the influence of age on the islet sst expression by studying female ICR mice at 6,20 , and 40 weeks of age and male ICR mice at 11 and 20 weeks of age. With the possible exception of sst3, which declined in the 20week-old mice in contrast to an increase in diabetic NOD mice, no age-related change was found in the female ICR mice. In addition, Fig. 5B shows that there was no alteration in expression of any of the five ssts when comparing younger male ICR mice with older mice. Since there was an increase of sst3 and 4 expression in relation to age in diabetic NOD mice compared with male NOD mice (data not shown), we postulate that the observed alterations in sst expression depend on the progression of disease and/or extent of insulitis rather than increasing age.

We found that the frequency of sst 1 expression was not altered in the pancreatic islets of diabetic NOD mice compared with normal females at any age interval or insulitis rank, when islets were evaluated on the basis of receptor expression or not (Figs 3 and 4). The sst1 receptor was observed to be expressed mainly in the centre of the islet. Most $\beta$-cells in C57BL/6 mice have recently been shown to be sst1-positive (21), but in the NOD mice not more than $35 \%$ of the normal females and $5 \%$ of the diabetic NOD mice co-expressed sst1 on $\beta$-cells (Fig. 6A). Moreover, the occurrence of insulitis led to a lower sst 1 expression on $\beta$-cells compared with animals lacking insulitis (Table 2). It was noted that of the different receptor subtypes, sst1 was most extensively expressed in the pancreas of normoglycaemic female NOD mice (67\%), followed closely by sst 2 , whereas instead sst 5 was most frequently expressed in the islets of diabetic females (84\%; Fig. 3). The latter findings suggest that the physiological regulation of sst1 in $\beta$-cells is more influenced by the autoimmune inflammation of the pancreatic islets rather than by the hyperglycaemia/diabetes.

About half of the normoglycaemic females in this study expressed sst2 in their islets, whereas more than $80 \%$ of the diabetic animals displayed sst2 expression (Fig. 3). An immunoreactivity for sst2 in the acinar cells was also found, which is supported by other studies $(21,22)$. We observed that some of the normoglycaemic mice expressing sst2 showed a more pronounced peripheral immunostaining of the islet, with weak or no central immunoreactivity. Glucagon secretion has been reported to be regulated by sst 2 in mice (17), which may suggest a higher expression of sst2 in glucagon-positive cells compared with other islet cells. This is in line with our observation showing that co-expression of sst 2 on $\alpha$-cells was close to $100 \%$ in diabetic females and $73 \%$ in normoglycaemic NOD mice (Fig. 6B). A preferential peripheral islet-cell expression pattern, however, was not seen in the 

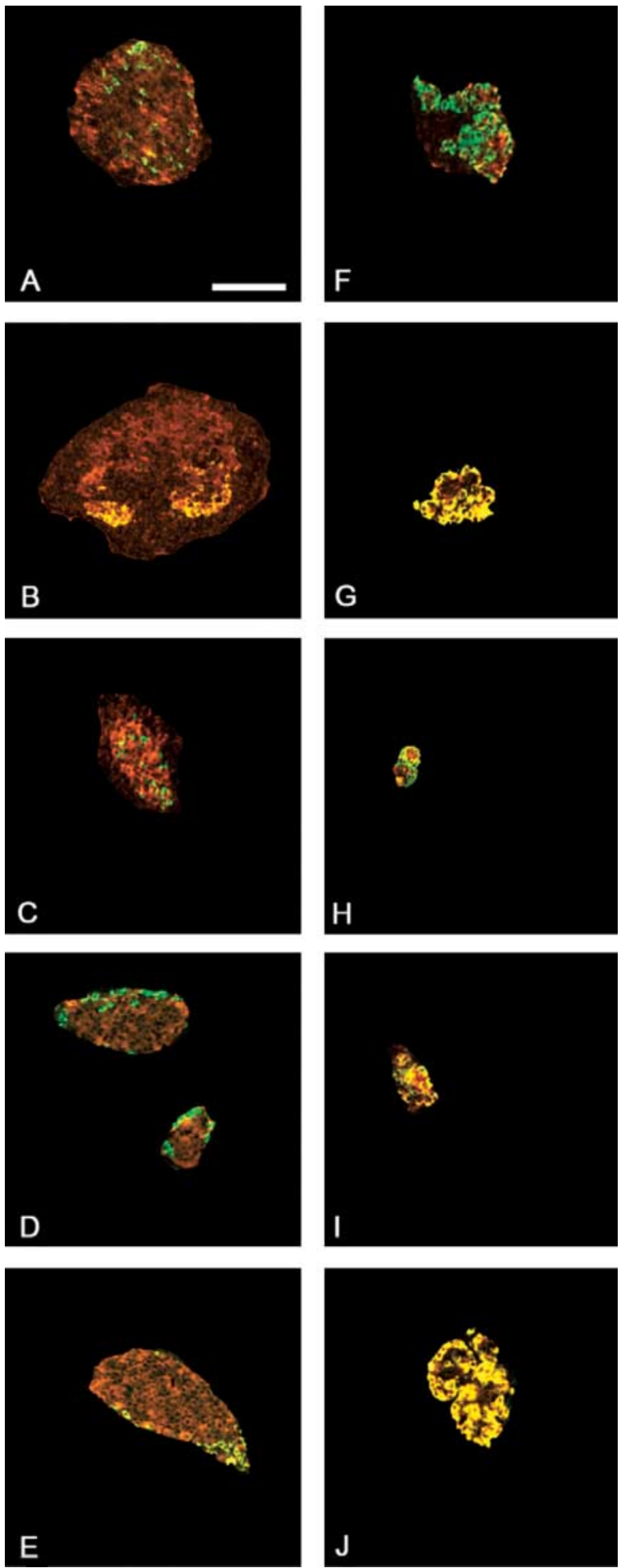

Figure 7 Pancreatic islets of a representative normoglycaemic female NOD mouse (A-E) and a representative diabetic NOD mouse $(F-J)$ from age group 4 . Red staining shows sst receptor staining, green staining shows glucagon-positive staining, and yellow staining shows co-expression of sst and glucagon. Scale bar, $50 \mu \mathrm{m}$. diabetic NOD mice and Fig. 7 shows that the islet architecture and cell distribution was altered when comparing the two groups. It seems that the $\alpha$-cells are more centred within the islets in the diabetic NOD mice compared with normoglycaemic mice. This is in line with previous studies (23). The high co-expression value is, however, almost the same in animals with or without insulitis and diabetes. In the diabetic animals no $\beta$-cells expressing sst2 were found (Fig. 6A), which could suggest that a somatostatin-induced inhibition of insulin release may not be possible to achieve in the hyperglycaemic mice. This circumstance would facilitate insulin secretion when insulin is lacking. Furthermore, this notion is corroborated by the observation that $\beta$-cell expression of sst 5 decreased in the diabetic females (Fig. 6A), since the latter receptor subtype is important for inhibition of insulin secretion. The importance of increased expression of sst 2 in $\delta$ - and PP cells of diabetic animals is unclear. Insulitis itself did not affect $\alpha$ - and $\beta$-cell expression of sst2, whereas it reduced the expression of this receptor in $\delta$ - and $\mathrm{PP}$ cells (Table 2). The majority of the infiltrating immune cells in the pancreatic islets of the NOD mice are T-cells, which are known to release pro-inflammatory cytokines such as interferon (IFN)- $\gamma$ and tumour necrosis factor- $\alpha$ (24). Furthermore, murine T-cells have been revealed to only express sst2. It has also been demonstrated that the synthetic analogue of somatostatin, octreotide, may inhibit antigen-stimulated secretion of IFN- $\gamma$ by T-cells in vitro (25). In agreement with this, a recent study showed that an anti-sst2A somatostatin receptor antibody could block the somatostatin-induced inhibition of IFN- $\gamma$ production (26). This could mean that locally released somatostatin in the inflammatory islet can down-regulate IFN- $\gamma$ secretion and then protect against cytokinemediated damage. Knowing that the immune cells may express sst 2 , we carefully investigated the islets for sst 2 expression so that the positive immunoreactivity reported herein should only refer to the islet cells, and not the invading immune cells. We found a higher frequency of animals expressing sst2 in pancreatic islet cells with some or massive infiltration of immune cells (Fig. 4). Since somatostatin is able to inhibit $\alpha$ - and $\beta$-cell function this might down-regulate glucagon secretion during a condition of increasing hyperglycaemia and render the remaining $\beta$-cells less vulnerable to cytokine-induced destruction during the development of insulitis. Thus, the increased expression of islet sst 2 receptors may reflect a defence mechanism by the islet cells against the secreted cytokines (27).

The expression pattern for sst 3 was similar to sst1, but was only detected in about $25 \%$ of the pancreatic islets of the normal female NOD mice. However, the expression of sst 3 was observed in about $60 \%$ of the islets of the diabetic animals (Fig. 3). In comparison, normal mouse islets have been reported to only express sst3 in a minority of the islet cells (21). The expression 
Table 2 Quantitative analysis of the expression of sst1-5 in the pancreatic islet cell types of normoglycaemic female NOD mice without invading immune cells $(A)$ from age group 1 and normoglycaemic female NOD mice from age group 4 with immune cells (B/C).

\begin{tabular}{|c|c|c|c|c|c|c|c|c|c|c|}
\hline & \multicolumn{10}{|c|}{ Expression (\%) } \\
\hline & \multicolumn{2}{|c|}{ sst1 } & \multicolumn{2}{|c|}{ sst2 } & \multicolumn{2}{|c|}{ sst3 } & \multicolumn{2}{|c|}{ sst4 } & \multicolumn{2}{|c|}{ sst5 } \\
\hline & A & $\mathrm{B} / \mathrm{C}$ & A & $B / C$ & A & $\mathrm{B} / \mathrm{C}$ & $A$ & $B / C$ & $A$ & $B / C$ \\
\hline$\beta$-Cells & $83 \pm 13$ & $35 \pm 11^{*}$ & $73 \pm 3$ & $88 \pm 8$ & $74 \pm 7$ & $36 \pm 12$ & $74 \pm 5$ & $48 \pm 8$ & $49 \pm 20$ & $61 \pm 5$ \\
\hline$\alpha$-Cells & $55 \pm 9$ & $14 \pm 4^{* *}$ & $96 \pm 2$ & $73 \pm 14$ & $75 \pm 7$ & $9 \pm 8^{* *}$ & $42 \pm 26$ & $7 \pm 2$ & $93 \pm 2$ & $85 \pm 3$ \\
\hline$\delta$-Cells & $84 \pm 9$ & $45 \pm 6^{*}$ & $96 \pm 4$ & $39 \pm 3^{\star *}$ & $69 \pm 2$ & $67 \pm 4$ & $57 \pm 2$ & $63 \pm 2$ & $49 \pm 6$ & $49 \pm 10$ \\
\hline PP cells & $29 \pm 1$ & $36 \pm 6$ & $30 \pm 6$ & $4 \pm 2^{\star \star}$ & $36 \pm 13$ & $44 \pm 10$ & $59 \pm 9$ & $54 \pm 11$ & $100 \pm 0$ & $28 \pm 4^{\star *}$ \\
\hline
\end{tabular}

Results are expressed as means \pm S.E.M. $(n=5)$ from the percentage of cells positive for a given sst subtype. ${ }^{\star} P<0.05$, ${ }^{*} P<0.01$ versus rank $\mathrm{A}$ for the respective sst and cell type.

seemed to be higher in diabetic animals compared with normal females in pancreatic sections with less islet inflammation, i.e. rank B (Fig. 4). The co-expression of sst 3 on $\alpha$-cells was found to be about $60 \%$ in diabetic NOD mice compared with $10 \%$ in normoglycaemic mice. However, animals without insulitis had also a high co-expression of sst 3 on $\alpha$-cells. In $\delta$-cells almost half of the cells expressed sst3, whereas the PP cells in diabetic animals did not express sst 3 at all in diabetic animals. This may suggest that sst 3 expression is affected by the diabetes progression, but not by the influence of infiltrating immune cells. The function of sst3 in pancreatic islet cells is presently unknown and needs further investigation.

In the present report we observed about $10 \%$ of the normal female NOD mice were found positive for islet sst4 expression. More diabetic animals compared with normoglycaemic NOD mice showed expression of sst4 (Fig. 3). The distribution of the receptor was similar to sst1 and 3. Normal mouse islet cells have been reported to express sst4 to a lower degree (21). Interestingly, the receptor was co-expressed in $50-80 \%$ in $\alpha$-, $\delta-$, and PP cells in diabetic NOD mice, and not at all in $\beta$-cells. However, sst4 is the receptor subtype that has been studied the least and the function of sst 4 in islets cells is essentially unknown.

sst5 is an important receptor subtype in inhibiting secretion of hormones from endocrine cells $(28-30)$. About $50 \%$ of the normal females and $85 \%$ of diabetic NOD mice were found immunoreactive for sst5 in their islets (Fig. 3). This receptor expression correlated with increasing age (data not shown) and insulitis score B (Fig. 4). A more pronounced peripheral immunoreactivity in the islets, as for sst2, was also observed in the majority of normal females. However, unlike sst2, this staining pattern was detected in a third of the diabetic females. sst 5 was found, together with sst 2 , to be co-expressed in $100 \%$ of $\alpha$-cells in diabetic animals. Insulin secretion has been reported to be inhibited mainly by activation of sst 5 in both human (31) and mouse $(17,18)$ islets. The immunofluorescence study of diabetic animals showed $11 \%$ co-expression of sst5 on $\beta$-cells compared with $61 \%$ in normoglycaemic animals in the same age group. Our results may suggest that sst5 may also be involved in several other functions in the pancreatic islets, for example inhibition of glucagon release, but further studies are needed to confirm this.

In conclusion, we found a higher frequency of diabetic female NOD mice showing sst $2-5$ expression in their pancreatic islet cells compared with normoglycaemic females. This correlated with increasing age and extent of insulitis. The changed sst $2-5$ expression in the islets cells of diabetic mice may suggest that ssts are either a contributing factor to, or a defence response against, ongoing $\beta$-cell destruction and hyperglycaemia. We also found that the islet architecture and co-expression of ssts with islet hormones were altered in diabetic animals. The present investigation of sst subtype expression in islet cells of NOD mice at different stages of disease may provide useful information for understanding islet function, and be of interest if attempts are performed to modulate progression of type 1 diabetes by somatostatin analogues.

\section{Acknowledgements}

The technical expertise of I-B Hallgren and E Törnelius is gratefully acknowledged. This study was supported by grants from the Swedish Research Council (72X8273), the Swedish Diabetes Association, the Swedish Cancer Foundation, the Novo Nordisk Foundation, the Family Ernfors Fund, the Juvenile Diabetes Foundation International, the Wallenberg Fund, and the Lions Foundation for Cancer Research at the University Hospital, Uppsala, Sweden.

\section{References}

1 Atkinson MA \& Leiter EH. The NODmouse model of type 1 diabetes: as good as it gets? Nature Medicine $19995601-604$.

2 Lampeter EF, Signore A, Gale EAM \& Pozzilli P. Lessons from the Nod mouse for the pathogenesis and immunotherapy of human type-1 (insulin-dependent) diabetes-mellitus. Diabetologia 1989 32 703-708. 
3 Leiter EH, Prochazka M \& Coleman DL. The nonobese diabetic (Nod) mouse. American Journal of Pathology 1987128 380-383.

4 Tochino Y. The NOD mouse as a model of type I diabetes. Critical Review of Immunology $1987 \mathbf{8}$ 49-81.

5 Thomas HE \& Kay TWH. Beta cell destruction in the development of autoimmune diabetes in the non-obese diabetic (NOD) mouse. Diabetes-Metabolism Research and Reviews 200016 251-261.

6 Yamada Y, Reisine T, Law SF, Ihara Y, Kubota A, Kagimoto S, Seino M, Seino Y, Bell GI \& Seino S. Somatostatin receptors, an expanding gene family: cloning and functional characterization of human SSTR3, a protein coupled to adenylyl cyclase. Molecular Endocrinology 19926 2136-2142.

7 Yamada Y, Post SR, Wang K, Tager HS, Bell GI \& Seino S. Cloning and functional characterization of a family of human and mouse somatostatin receptors expressed in brain, gastrointestinal tract, and kidney. PNAS $199289251-255$.

8 Yamada Y, Kagimoto S, Kubota A, Yasuda K, Masuda K, Someya Y, Ihara Y, Li O, Imura H, Seino S \& Seino Y. Cloning, functional expression and pharmacological characterization of a fourth (hSSTR4) and a fifth (hSSTR5) human somatostatin receptor subtype. Biochemical and Biophysical Research Communication $1993195844-852$.

9 Fehlmann D, Langenegger D, Schuepbach E, Siehler S, Feuerbach D \& Hoyer D. Distribution and characterisation of somatostatin receptor mRNA and binding sites in the brain and periphery. Journal of Physiology (Paris) 200094 265-281.

10 Kulaksiz H, Eissele R, Rossler D, Schulz S, Hollt V, Cetin Y \& Arnold R. Identification of somatostatin receptor subtypes 1 , $2 \mathrm{~A}, 3$, and 5 in neuroendocrine tumours with subtype specific antibodies. Gut $2002 \mathbf{5 0} 52-60$.

11 Portela-Gomes GM, Stridsberg M, Grimelius L, Oberg K \& Janson ET. Expression of the five different somatostatin receptor subtypes in endocrine cells of the pancreas. Applied Immunohistochemistry and Molecular Morphology 20008 126-132.

12 Reubi JC, Kappeler A, Waser B, Schonbrunn A \& Laissue J. Immunohistochemical localization of somatostatin receptor sst2A in human pancreatic islets. Journal of Clinical Endocrinology and Metabolism 199883 3746-3749.

13 Raulf F, Perez J, Hoyer D \& Bruns C. Differential expression of five somatostatin receptor subtypes, SSTR1-5, in the CNS and peripheral tissue. Digestion 199455 (Suppl 3) 46.

14 Koerker DJ, Ruch W, Chideckel E, Palmer J, Goodner CJ, Ensinck J \& Gale CC. Somatostatin: hypothalamic inhibitor of the endocrine pancreas. Science $1974 \mathbf{1 8 4} 482-484$.

15 Kimura N, Schindler M, Kasai N \& Kimura I. Immunohistochemical localization of somatostatin receptor type $2 \mathrm{~A}$ in rat and human tissues. Endocrine Journal 2001 48 95-102.

16 Mitra SW, Mezey E, Hunyady B, Chamberlain L, Hayes E, Foor F, Wang Y, Schonbrunn A \& Schaeffer JM. Colocalization of somatostatin receptor sst5 and insulin in rat pancreatic betacells. Endocrinology $19991403790-3796$.

17 Strowski MZ, Parmar RM, Blake AD \& Schaeffer JM. Somatostatin inhibits insulin and glucagon secretion via two receptor subtypes: an in vitro study of pancreatic islets from somatostatin receptor 2 knockout mice. Endocrinology 2000141 111-117.

18 Strowski MZ, Kohler M, Chen HY, Trumbauer ME, Li ZH, Szalkowski D, Gopal-Truter S, Fisher JK, Schaeffer JM, Blake AD, Zhang BB \& Wilkinson HA Somatostatin receptor subtype 5 regulates insulin secretion and glucose homeostasis. Molecular Endocrinology $20031793-106$.
19 Cejvan K, Coy DH \& Efendic S. Intra-islet somatostatin regulates glucagon release via type 2 somatostatin receptors in rats. Diabetes $2003521176-1181$.

20 Fagan SP, Azizzadeh A, Moldovan S, Ray MK, Adrian TE, Ding X, Coy DH \& Brunicardi FC. Insulin secretion is inhibited by subtype five somatostatin receptor in the mouse. Surgery $1998 \mathbf{1 2 4}$ 254-258.

21 Ludvigsen E, Olsson R, Stridsberg M, Janson ET \& Sandler S. Expression and distribution of somatostatin receptor subtypes in the pancreatic islets of mice and rats. Journal of Histochemistry and Cytochemistry 200452 391-400.

22 Hunyady B, Hipkin RW, Schonbrunn A \& Mezey E. Immunohistochemical localization of somatostatin receptor sst $2 \mathrm{~A}$ in the rat pancreas. Endocrinology 1997138 2632-2635.

$23 \mathrm{Li} \mathrm{Z}$, Karlsson FA \& Sandler S. Islet loss and alpha cell expansion in type 1 diabetes induced by multiple low-dose streptozotocin administration in mice. Journal of Endocrinology 2000165 93-99.

24 Suarez-Pinzon W, Rajotte RV, Mosmann TR \& Rabinovitch A. Both $\mathrm{CD} 4+$ and CD8 + T-cells in syngeneic islet grafts in NOD mice produce interferon-gamma during beta-cell destruction. Diabetes $1996 \mathbf{4 5} 1350-1357$.

25 Blum AM, Metwali A, Mathew RC, Cook G, Elliott D \& Weinstock JV. Granuloma T lymphocytes in murine schistosomiasis mansoni have somatostatin receptors and respond to somatostatin with decreased IFN-gamma secretion. Journal of Immunology $1992 \mathbf{1 4 9} 3621-3626$.

26 Elliott DE, Li J, Blum AM, Metwali A, Patel YC \& Weinstock JV. SSTR2A is the dominant somatostatin receptor subtype expressed by inflammatory cells, is widely expressed and directly regulates T cell IFN-gamma release. European Journal of Immunology 1999 $292454-2463$.

27 Eizirik DL, Sandler S \& Palmer JP. Repair of pancreatic beta-cells. A relevant phenomenon in early IDDM? Diabetes $1993 \mathbf{4 2}$ 1383-1391.

28 Buscail L, Esteve JP, Saint-Laurent N, Bertrand V, Reisine T, O'Carroll AM, Bell GI, Schally AV, Vaysse N \& Susini C. Inhibition of cell proliferation by the somatostatin analogue RC-160 is mediated by somatostatin receptor subtypes SSTR2 and SSTR5 through different mechanisms. PNAS 199592 $1580-1584$.

29 Cattaneo MG, Scita G \& Vicentini LM. Somatostatin inhibits PDGF-stimulated Ras activation in human neuroblastoma cells. FEBS Letters $1999 \mathbf{4 5 9} 64-68$.

30 Cordelier P, Esteve JP, Bousquet C, Delesque N, O'Carroll AM, Schally AV, Vaysse N, Susini C \& Buscail L. 1997 Characterization of the antiproliferative signal mediated by the somatostatin receptor subtype sst5. PNAS 94 9343-9348.

31 Zambre Y, Ling Z, Chen MC, Hou X, Woon CW, Culler M, Taylor JE, Coy DH, Van Schravendijk C, Schuit F, Pipeleers DG \& Eizirik DL. 1999 Inhibition of human pancreatic islet insulin release by receptor-selective somatostatin analogs directed to somatostatin receptor subtype 5. Biochemical Pharmacology $1999571159-1164$.

Received 12 April 2005

Accepted 21 June 2005 